\title{
DEVELOPING AND SUPPORTING COORDINATORS OF STRUCTURED MENTORING SCHEMES IN SOUTH AFRICA
}

\section{Authors:}

Penny Abbott ${ }^{1}$

Xenia Goosen ${ }^{1}$

Jos Coetzee ${ }^{1}$

\section{Affiliations:}

'Department of Industrial

Psychology and People

Management, University of

Johannesburg, South Africa

\section{Correspondence to:}

Penny Abbott

email:

pennyabbott@mweb.co.za

\section{Postal address:}

4a Birnam Road, Forest

Town, Johannesburg 2193,

South Africa

\section{Keywords:}

Mentoring; mentoring scheme coordinator; functions of mentoring scheme coordinators; people development; South African context

\section{Dates:}

Received: 16 Nov. 2009

Accepted: 29 July 2010

Published: 22 Oct. 2010

\section{How to cite this article:}

Abbott, P., Goosen, X.,

\& Coetzee, J. (2010).

Developing and supporting coordinators of structured mentoring schemes in South Africa. SA Journal of Human Resource Management/SA Tydskrif vir Menslikehulpbronbestuur, 8(1), Art. \#268, 10 pages. DOI: 10.4102/sajhrm.v8i1.268

\section{This article is available} at:

http://www.sajhrm.co.za
(C) 2010. The Authors. Licensee: OpenJournals Publishing. This work is licensed under the Creative Commons

\begin{abstract}
Orientation: Mentoring is considered to be such an important contributor to accelerated people development in South Africa that structured mentoring schemes are often used by organisations. There are at present few sources of development and support for coordinators of such schemes.

Research purpose: The aim of this research is to discover what the characteristics of coordinators of structured mentoring schemes in South Africa are, what is required of such coordinators and how they feel about their role, with a view to improving development and support for them.
\end{abstract}

Motivation for the study: The limited amount of information about role requirements for coordinators which is available in the literature is not based on empirical research. This study aims to supply the empirical basis for improved development and support for coordinators.

Research design and method: A purposive sample of 25 schemes was identified and both quantitative and qualitative data, obtained through questionnaires and interviews, were analysed using descriptive statistics and thematic analysis.

Main findings: Functions of coordinators tend to be similar across different types of mentoring schemes. A passion for mentoring is important, as the role involves many frustrations. There is little formalised development and support for coordinators.

Practical/managerial implications: The study clarifies the functions of the coordinator, offers a job description and profile and makes suggestions on how to improve the development of the coordinator's skills.

Contribution/value-add: An understanding of what is required from a coordinator, how the necessary knowledge and skills can be developed and how the coordinator can be supported, adds value to an organisation setting up or reviewing its structured mentoring schemes.

\section{INTRODUCTION}

Mentoring is an accepted and popular process, in use in many diverse settings internationally and across South Africa - for example, in education, community development, health, small business development, broad-based black economic empowerment and formal organisations. Almost every day the term 'mentor' is heard in the media - often where a successful person is giving recognition to someone who helped them along the way. Many of these mentoring relationships occur informally, driven by mentees looking for a role model or someone to help them. In addition, though more formal, mentoring relationships are established through structured mentoring schemes, which are managed by coordinators.

Mentoring is seen as a potentially powerful source of people development and many examples of significant transitions and growth are given in both academic and popular sources (for example, in Clutterbuck, 2001; Evans, 2003; Freedman, 1999; Gilmore, Coetzee \& Schreuder, 2005; Kochan \& Pascarelli, 2003; Stewart \& Parr, 2008). Hence there is a high degree of interest in mentoring in South Africa, where there is great need for accelerated individual development as well as for various types of societal and community development. Research has shown that if mentoring is chosen as a process with a specific objective in mind (for example, growth of a small business, or to help someone with the transition to a new management level), it is more likely to be successful if it takes place within a structured scheme (Klasen \& Clutterbuck, 2002). This structured scheme has to be run by someone. However, little attention is paid to the role this person plays, even though this role is acknowledged to be a critical success factor for the mentoring scheme (Clutterbuck, 2001; Forret, 1996; Freedman, 1999; Murray, 2001).

The job of mentoring scheme coordinator is not particularly easy - far from it.It demands a deep understanding of the nature and dynamics of mentoring, and a remarkable store of patience, tenacity and political skill. Yet we have never encountered a scheme coordinator who did not enjoy the role and feel motivated to do more of it.

(Klasen \& Clutterbuck, 2002, p. xiii)

\section{The context of the work of the mentoring scheme coordinator}

The context of the work of mentoring scheme coordinators could impact them in various ways, for example, the functions the coordinator may be asked to perform and the difficulties the coordinator might be likely to face could be influenced by the type of organisation running the mentoring scheme, the scope and purpose of the scheme and other factors such as the size of the scheme. Gibb and Megginson (1993) argue that the context within which a mentoring scheme operates influences the scheme tremendously and therefore the adaptation of the scheme framework to suit its context is one of the critical success factors for the scheme. 
It is also important, when considering the support of coordinators, to consider the size and diversity of the population of mentoring schemes in South Africa. If there is a large number of mentoring schemes, there is a commensurately large number of coordinators and it would be viable to put together some sort of development network or support initiatives. The degree of similarity or difference between mentoring schemes would influence the degree to which coordinators could find common experiences in their networking and therefore the degree to which such networks would be of practical use.

However, information on the number and nature of mentoring schemes in South Africa is difficult to access. There are indications that the number of schemes should be large since, for example, Government and public policy appears to be supportive of the concept of mentoring (DPSA, 2006; DME, 2009; EPWP, 2009; Jobs Summit, 1998). All learnerships run under the auspices of the Sector Education and Training Authorities are supposed to have a mentorship component. Mentoring, as a developmental relationship, is likely to be a key component of employment equity plans and any diversity management programmes that an organisation may have in place. In addition, newspapers, magazines and the internet over the period 2006-2008 have often mentioned a variety of mentoring schemes aimed at, for example, first-year undergraduates, candidate and junior female accountants, women in the IT industry, municipality managers, microenterprise owners, youth entrepreneurs, children at risk and women in business and government. It can be inferred from this and from the public policy support, that there are many mentoring schemes operating in South Africa. However, there is no directory or other form of systematic knowledge of these and it is difficult to trace and make contact with coordinators of these schemes.

Lack of integration of good practice and experience across schemes, which is seen as a problem overseas (Clutterbuck, 2001), is even more of an issue in South Africa because of the lack of easily-accessible information in terms of mentoring schemes. This can impact significantly on the ability of the designer and implementer of a mentoring scheme (usually also the coordinator of the scheme) to access good practice from similar schemes and would probably result in many unnecessarily repeated mistakes. In the UK, an organisation called Mentfor was set up to try to remedy this lack and bring together knowledge on mentoring schemes (Mentfor 2009), while in North America, the International Mentoring Association Peer Resources Network has similar aims (IMA, 2009; Peer Resources Network, 2009). The possibility of creating such a resource in South Africa is explored in the Discussion section of this article.

The coordinator must structure his or her scheme around the needs that the scheme seeks to meet. In the study carried out by Meyer and Steinmann (2008), reasons for the introduction of coaching and mentoring schemes in formal organisations include management development, talent management, enhancing competency, sustainability, employee retention, succession planning, skills shortages, graduate development, employment equity, workplace skills plans, learnerships and professional requirements. The various aims of mentoring schemes in other types of organisations have been described earlier.

Increasing emphasis is being placed on the evaluation of mentoring schemes, which has a big impact on the work of the coordinator. Clutterbuck $(2003$, p. 262) states that 'a high proportion of all mentoring programmes fade away. Surprisingly, there has been very little research into the reasons why some flourish and others do not'. Garvey and Carter (2004) note that care must be taken when measuring outcomes because 'measurement can become a controlling device that may distort social and work-based activities', implying that managing a scheme strictly towards measurable results may distort the spirit of what is intended. In the 2008 Meyer and Steinmann study, $58 \%$ of respondents said that the programme was evaluated through performance management, $43 \%$ through competence assessment and $20 \%$ through business impact. However, the value of this finding is limited by the lack of differentiation between mentoring and coaching in the study.

Conway (1998) mentions that, in change management processes, failure is easier to measure than success and he believes this could be true of mentoring as well. Colley (2003) argues that some mentoring outcomes have not necessarily been intended originally, but these unintended outcomes should not be undervalued - if the mentee perceives value in the relationship it is a success. She sees the frequent emphasis on 'hard' outcomes as undermining the benefits of 'soft' outcomes and quotes Egan (1994), who argues that helping must have goals that are consistent with the client's own values, and the client must feel ownership of those goals. This would seem to support the notion that success is a complex issue in mentoring schemes, which could make it difficult for the coordinator to demonstrate the success of his or her scheme.

\section{The role, functions and profile of the coordinator}

The literature reviewed does not have extensive reference to the role and function of the scheme coordinator. Freedman (1999, p. 92) devotes a chapter to 'making the most of mentoring', in which he refers to 'fervor without infrastructure'. He describes how champions of mentoring tend to take an inspirational approach to setting up a scheme rather than putting in place the organisational infrastructure to ensure success. Shiner, Young, Newburn and Groben (2004, p. 71) refer to 'a significant body of research that shows that implementation failure - or at least inadequate implementation - often lies at the heart of the inability to deliver better outcomes'.

There is little consensus on the best structure, process flow or elements of a structured mentoring scheme (Gibb \& Megginson, 1993; Klasen \& Clutterbuck, 2002; Murray, 2001; Philips \& Stromei, 2001). Hattingh, Coetzee and Schreuder (2005) describe a set of six best practices derived from other literature. These are:

1. preparing the implementation proposal and conducting the necessary research

2. identifying key stakeholders and gaining organisational commitment

3. marketing

4. design and development

5. maintenance, concluding and further development

6. evaluation and review.

In an effort to contribute to good practice in this area, the European Mentoring and Coaching Council has endorsed a set of International Standards for Mentoring Programmes in Employment (ISMPE) built around the following six standards (ISMPE, 2009):

1. clarity of purpose

2. stakeholder training and briefing

3. processes for selection and matching

4. processes for measurement and review

5. high standards of ethics

6. administration and support.

The functions of the coordinator or coordination team are reviewed by Clutterbuck (2001), Kochan (2002) and Murray (2001). Although a range of tasks are proposed the topic is treated in a few sentences in each source rather than being covered extensively. The South African company Anglo Platinum is clear on its expectations regarding the coordinator's functions:

coordinators at all operations are trained on the mentorship programme and are accountable for identifying mentors, identifying mentees according to the mentorship policy; training mentors and mentees; matching mentors to mentees; and monitoring progress of the relationships.

(AngloPlat, 2009) 
There is little literature on how many people are required to manage a mentoring scheme and what their specific tasks should be. In the study by Hattingh et al. (2005), the authors refer to the number of people assigned to the scheme, but do not discuss the scale of the scheme, so it is difficult to determine whether the level of resourcing is high or not.

As mentioned previously, the issue of what results the coordinator is expected to deliver is somewhat complex. Even the nature of reporting on progress and results can be problematic. Colley $(2003$, p. 172) refers to the 'atomising effects of individual mentoring', meaning that simply reporting on outcomes for the mentoring pairs can miss significant lessons for the organisation if feedback and themes coming out of the mentoring discussions can somehow be consolidated without compromising the confidentiality of the discussions.

Other influences on the functions and scope of the coordinator's role can include, (1) ethics (including the issue of sexual harassment, the degree to which other interested parties are kept informed about the mentoring, unintentional exclusion of groups of employees and confidentiality within the mentoring discussions) as covered by Klasen and Clutterbuck (2002), (2) the ease or difficulty of obtaining funding (unpublished evaluation report by R. White, according to T. Martin, personal communication, September 30, 2008) and (3) the use of technology to manage the scheme. In cases where the mentors are volunteers, coordinators must also pay attention to maintaining their interest and involvement (Freedman, 1999).

There are few references in the literature reviewed to the required profile of the coordinator (Colley, 2003; Conway, 1998; Freedman, 1999; Klasen \& Clutterbuck, 2002; Murray, 2001). Knowledge of the organisation, expertise in mentoring, intuition, facilitation skills, marketing and selling skills, project management skills and practical organisational skills are regarded as important. There are few references to the recruitment, training and development of coordinators. This would tend to support the anecdotal evidence that people become coordinators either by chance or by being passionate about mentoring and volunteering to take on the role. Klasen and Clutterbuck (2002) mention that a background in training or as an experienced human resources facilitator is helpful for the coordinator. In community-based or education-based mentoring schemes, a professional background as a social worker or educator is common (Colley, 2003; Freedman, 1999).

Development activities referred to in the literature are mainly confined to support methods such as conferences and networks (Freedman, 1999; Mentfor, 2009; Peer Resources Network, 2009). There is a Unit Standard in the South African National Qualifications Framework referring to managing mentoring programmes but this is limited to a school setting and the programme manager has to be a school manager (SAQA, 2009).

\section{Research problem and objectives}

The literature review shows that, while the coordinator is a key factor in the success of a mentoring scheme, there is no empirical research into the role of the mentoring scheme coordinator. A research study was therefore conducted on several aspects of the role and development of the mentoring scheme coordinator to contribute to better knowledge in this field and thereby to improving the probability of success in delivering the desired mentoring outcomes.

The question can be posed as to what are the characteristics and experiences of the coordinators of mentoring schemes. Relevent to this study, the research objectives were to:

- Collect information on the characteristics of the coordinators of structured mentoring schemes in a wide range of societal institutions.

- Collect information on what is required of the coordinators.

- Discover how coordinators experience their role.
- Identify and explore themes which can lead to an understanding of how best to support and develop the coordinators.

For the purpose of this research study, the following definition of mentoring has been adopted, based on Clutterbuck (2001). Mentoring occurs in a relationship and consists of off-line help by one person to another in making significant transitions in knowledge, work, thinking or coping with life challenges. The discussion agenda within the relationship is determined by the mentee and the mentor can play various roles and adopt a broad range of approaches in helping the mentee.

\section{RESEARCH DESIGN}

\section{Research approach}

Research in the social sciences can adopt either a positivist or an interpretive approach (Bryman \& Bell, 2003; Cresswell, 2003; Denzin \& Lincoln, 2005). The positivist approach derives from the natural sciences and takes place in a paradigm that reality is objectively determinable and therefore firm conclusions can be drawn about cause and effect in social sciences. This approach adopts quantitative methodologies. The interpretive approach evolved as researchers recognised that reality is different for different people and reality derives meaning through human experiences and perceptions. Qualitative methodologies are used in the interpretive approach. Cresswell (2003) recorded the development of mixed method research from about 1959 onwards and recommends the use of research methods drawing on both paradigms in order to overcome the limitations of each.

This research study was informed by Cresswell (2003) and adopted both quantitative and qualitative methodologies because the nature of the research objectives included both objectively verifiable variables such as the age or education level of the coordinator and highly subjective topics such as the personal experience and perceptions of the coordinators. It is proposed that some of the quantitatively analysed variables together describe a context within which each coordinator experiences his or her role. Colley $(2003$, p. 161) argues that mentoring is a topic which is not clearly conceptualised with no clear theory base and therefore researching the mentoring process should not use quantitative methods - she views responsible research as 'an engaged social science that grounds itself in the experiences of the field [...] to do justice to the meanings they make in practice'. This research study was interested in the meanings that coordinators make in relation to their experiences in running mentoring schemes.

Data on various mentoring schemes was obtained through a research questionnaire, to enable cross-sectional and comparative analyses from which commonalities and differences could be derived. It was hoped that these could then inform some good practice models or descriptions. In addition to the quantitative part of this research study, a basic qualitative design was used, as described by Merriam (1998) in that it 'includes description, interpretation and understanding; it identifies recurrent patterns in the form of themes or categories; and it may describe a process'. Data for the qualitative study was obtained from open-ended questions in the questionnaire as well as from follow-up interviews with selected coordinators.

\section{Research strategy}

The research strategy adopted in this study was to identify coordinators of mentoring schemes through references from various media sources, personal contacts and networking. An electronic questionnaire was then distributed, followed by interviews with coordinators. Themes for analysis in the qualitative part of the study were derived initially from the literature; these themes were confirmed and expanded based on responses to open questions in the questionnaire and from the interviews. 


\section{Research method Research setting}

The setting for the research study was varied, as the coordinators work in organisations as diverse as corporate, government agencies, non-profit organisations and universities. Each of the study participants was approached in their normal work setting.

\section{Entrée and establishing researcher role}

The researcher personally contacted each of the prospective respondents and explained the context and purpose of the study before asking for their agreement to participate. The role of the researcher was that of an 'informed outsider' - that is, someone who was knowledgeable about the topic but not about each coordinator's particular setting.

\section{Sampling}

The unit of analysis in this study is the coordinator of the mentoring scheme. In order to access these coordinators, the population of mentoring schemes in South Africa, which is currently unknown, had to be explored from accessible sources of information such as newspapers, magazines and the internet. The decision on inclusion or exclusion of a mentoring scheme on the basis of whether it met the criteria for a structured mentoring scheme was made largely by self-selection on the part of prospective respondents, based on whether they could meaningfully answer the questionnaire items. The identification of respondents was carried out on the basis of asking who had the main responsibility for the mentoring scheme - that person then completed the research questionnaire.

A purposeful sample of mentoring schemes, aimed at choosing a sample from which the most can be learned (Merriam, 1998), was drawn from schemes identified in the manner described above to complete the research questionnaire. The sample was representative of corporate, public sector and voluntary sector schemes, as well as both large and small schemes. The sample was obtained by approaching coordinators and inviting participation through telephonic discussion.

The sample of coordinators for the interviews was chosen from the pool of questionnaire respondents on the basis of a theoretical sample - described by Merriam (1998, pp. 63-64) as 'an evolving process, guided by the emerging theory, yielding reasonable coverage [...] given the purpose of the study' - and also following the approach of maximum variation sampling. A reasonable cross-section of corporate and voluntary sector schemes, as well as large and small schemes, was pursued.

Within this cross-section, questionnaire respondents who seemed to represent the richest sources of data were approached - for example, the scheme had been running for some time, was a large scheme, was in an unusual setting or the coordinator had an unusual background. This yielded a sample of seven interviewees, which fitted the scope and timescale of the research study.

A total of 177 potential respondents were identified but many of these could not be traced and contacted, so 67 research questionnaires were sent out. Only 25 useable responses were obtained, giving a response rate of $37 \%$. A satisfactory spread of demographic variables of the schemes was obtained, as shown in Table 1. A total of seven interviews were held with coordinators.

\section{Data collection methods}

Data was collected through an electronic questionnaire and also through individual interviews. The questionnaire was designed by means of the tool provided by the web survey provider Survey Monkey and was designed for a more extensive research study, only part of which has been reported in this article. The questionnaire was structured into sections and contained both tick-box questions and questions allowing free-text responses. The relevant sections of the questionnaire covered:

- Information on the organisation running the mentoring scheme

Type of organisation and, in cases where the organisation is a business, the economic sector

- Demographic information on the coordinator (the respondent)

Variables such as age, gender and educational standard

- Information on the mentoring scheme itself

Variables relevant to this article included the scale and scope of the scheme plus scheme longevity

- Information on management and resourcing of the mentoring scheme

How many people was involved in running the scheme, job title of the coordinator, the use of IT, who performed which functions, the existence of a steering committee

- Information on the coordinator

The full-time or part-time nature of the role, length of time in the role, reporting relationship, how the person took on the role, clarity of role, previous experience, satisfiers and dissatisfiers in the role, important skills and developmental experiences.

Respondents were given three alternative ways of completing the questionnaire, (1) via the web site, (2) using a PDF file, or (3) by telephone interview. This was to ensure participation even from respondents with limited internet access. Six of the 25 respondents chose one of the two latter alternatives.

The interviews were conducted face to face (four interviews) or by telephone (three interviews). The interviews were approximately $30 \mathrm{~min}-45 \mathrm{~min}$ long; this was considered sufficient for a qualitative interview in view of the limited focus of the study and also because the interviewees had

TABLE 1

Demographics of mentoring schemes

\begin{tabular}{|c|c|c|c|c|c|c|c|c|c|}
\hline \multicolumn{2}{|c|}{ Types of organisation } & \multicolumn{2}{|c|}{ Economic sector of companies } & \multicolumn{2}{|c|}{ Location of mentors \& mentees } & \multicolumn{2}{|c|}{ Types of scheme } & \multicolumn{2}{|c|}{$\begin{array}{c}\text { Length of time scheme has been } \\
\text { running }\end{array}$} \\
\hline Description & $\mathbf{Q}$ & Description & $\mathbf{Q}$ & Description & $\mathbf{Q}$ & Description & $\mathbf{Q}$ & Description & $\mathbf{Q}$ \\
\hline Company & 10 & Financial services & 3 & Gauteng & 9 & $\begin{array}{l}\text { Internal mentors \& } \\
\text { mentees }\end{array}$ & 13 & Under 6 months & 3 \\
\hline Government owned & 1 & Manufacturing & 3 & Western Cape & 5 & $\begin{array}{l}\text { External mentors for } \\
\text { employees }\end{array}$ & 1 & 6 months to 1 year & 1 \\
\hline Public Service & 2 & Services & 1 & $\begin{array}{l}\text { Other major urban } \\
\text { centre }\end{array}$ & 1 & $\begin{array}{l}\text { External mentors \& } \\
\text { mentees }\end{array}$ & 7 & $\begin{array}{l}\text { Over } 1 \text { year, up to } 2 \\
\text { years }\end{array}$ & 4 \\
\hline Non-Profit & 5 & Mining & 1 & All over SA & 5 & $\begin{array}{l}\text { Mentors (employees) } \\
\text { supplied to external } \\
\text { mentees }\end{array}$ & 1 & $\begin{array}{l}\text { Over } 2 \text { years, up to } \\
5 \text { years }\end{array}$ & 9 \\
\hline Community- based & 2 & Other & 2 & Several urban centres & 4 & Mixed & 3 & Over 5 years & 8 \\
\hline Youth & 1 & - & - & Mainly rural & 1 & - & - & - & - \\
\hline Foundation & 3 & - & - & - & - & - & - & - & - \\
\hline Total & 25 & - & 10 & - & 25 & - & 25 & - & 25 \\
\hline
\end{tabular}


TABLE 2

Attributes of mentoring scheme

\begin{tabular}{|c|c|c|c|c|c|c|c|}
\hline \multicolumn{2}{|c|}{ Internal schemes - number of pairs } & \multicolumn{2}{|c|}{ External schemes - number of pairs } & \multicolumn{2}{|c|}{ Degree of structure } & \multicolumn{2}{|c|}{ Closeness of mentors and mentees } \\
\hline Description & $\mathbf{Q}$ & Description & $\mathbf{Q}$ & Description & $\mathbf{Q}$ & Description & $\mathbf{Q}$ \\
\hline None & 1 & None & 0 & Pretty unstructured & 0 & Geographically close & 23 \\
\hline Up to 5 pairs & 2 & Up to 5 pairs & 0 & $\begin{array}{l}\text { Mixture of structured and } \\
\text { unstructured }\end{array}$ & 14 & Geographically distant & 2 \\
\hline 6-20 pairs & 5 & 6-20 pairs & 6 & Pretty structured & 11 & - & - \\
\hline $21-50$ pairs & 2 & $21-50$ pairs & 3 & - & - & - & - \\
\hline 51-100 pairs & 1 & 51-100 pairs & 1 & - & - & - & - \\
\hline Over 100 pairs & 1 & Over 100 pairs & 3 & - & - & - & - \\
\hline Total & 12 & - & 13 & - & 25 & - & 25 \\
\hline
\end{tabular}

already completed a questionnaire. For the first three interviews, a largely unstructured format was followed. Even though the interviewees had completed a questionnaire already, the purpose of the interviews was to obtain much more personal insights, so these interviews were exploratory and non-directive. The later interviews were semi-structured and designed to follow up and validate themes arising in the earlier interviews. Shank (2002) describes the value of the use of metaphors to access the meanings that people make in their roles, so all interviewees were asked to give a metaphor for their experiences as a coordinator - this helped to gain an understanding of what meanings the interviewees were making for themselves in their role.

Reliability of the data collected was addressed by ensuring a good sample size, by ensuring that respondents had substantive experience as a coordinator and by ensuring that a cross-section of scheme types was covered in the interview sample. Consistency of responses was examined: this proved to be high between the interviewees, so it can be inferred that the data is valid.

\section{Recording of data}

All responses to the questionnaire were captured onto the web server data base. In the case of the questionnaires completed and sent in via email or through telephonic interviews, the researcher herself captured the responses onto the web server. Where typing errors had been made in the questionnaire's freetext responses, these were corrected on the web server. No other manipulation of the data was carried out. All the data was then downloaded into an Excel file, from where they were analysed.

The interviews were recorded on a digital recorder with the consent of the interviewee. The researcher then transcribed the interviews.

\section{Data analyses}

Basic descriptive statistical analyses were carried out on the quantitative data. In a few cases, further analysis was carried out to investigate some relationships and trends in the data. The qualitative data from the questionnaires and the interviews was analysed through iterative reviews - emerging issues were identified and checked with the later interviewees. Themes were then identified and constant cross-comparison of the transcripts was carried out manually on index cards to refine the relevant concepts and categories of the coordinators' experiences.

\section{Strategies employed to ensure data quality}

Care was taken in the initial approach to participants to ensure that they were indeed fulfilling the role of coordinator and could supply meaningful responses. Once questionnaires were received, the researcher checked them and phoned the respondent to clarify any apparent discrepancies.

\section{Reporting}

The findings are reported using two different styles to suit the two different types of data. The quantitative data is reported in descriptive statistics while the qualitative data is presented largely under the various themes extracted from the survey, using verbatim quotations as appropriate and paraphrases of responses which have been grouped together.

\section{FINDINGS}

The findings regarding contextual variables relating to the mentoring schemes such as type of organisation, scope and size of the mentoring scheme, how long the scheme has been running, types of mentors and how the scheme is evaluated are dealt with first, in order to describe the context within which coordinators work in this country. As discussed earlier, the context can influence the nature and scope of the work of coordinators and can have a big impact on their experiences.

\section{Contextual variables}

As indicated in Table 1, the coordinators are working in a variety of organisation types. The sample included mentoring schemes in many different settings including companies, educational and health institutions, foundations, youth organisations and the public sector. Over half (52\%) of the sampled schemes had been running for less than 2 years, while the modal group (36\%) had been running for between 2 and 5 years. Thirty-two per cent had been running for more than 5 years.

The size of schemes in the sample ranged from less than five mentoring pairs to more than a hundred pairs. Table 2 shows the distribution of schemes with reference to the variables of size, degree of structure and geographical closeness of mentoring pairs.

The sample showed examples of both volunteer and paid mentors, although only the external schemes (that is, those which employ external mentors for mentees who are also external to the organisation) pay their mentors anything more than a token amount. In addition, not all the external schemes use professional mentors; some use volunteers.

In terms of measurability of outcomes, most mentoring schemes state their purpose in fairly general terms, for example, 'to provide mentoring support to youth owned businesses', 'mentor employees who show potential', 'to transfer skills through mentoring relationship'. Not one scheme had a measurable, outcome-related purpose statement, although a few could be

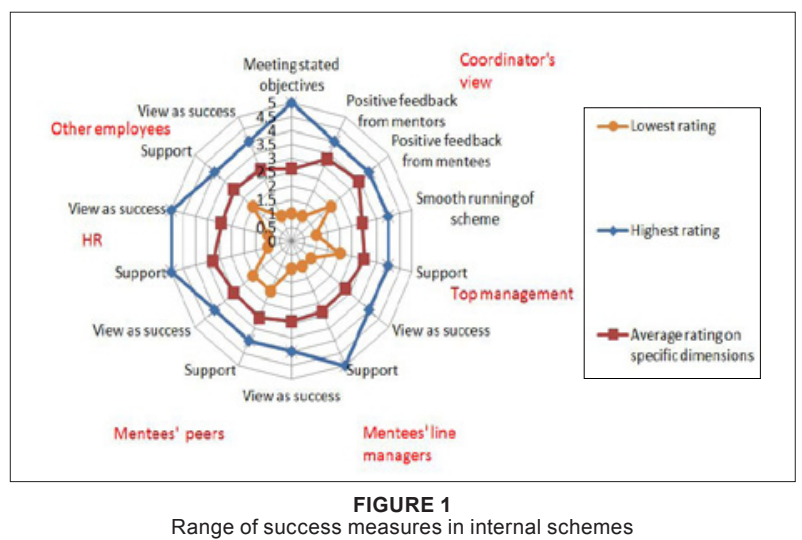


converted to measurable, outcome-related terms, for example, 'to increase at a faster pace the number of black people into the senior management levels of the organisation'. Possibly related to this lack of measurability of outcomes is the finding that $52 \%$ of the coordinators sampled reported that they have not formally evaluated their scheme. Respondents were asked to rate the reactions of the various stakeholders involved in the mentoring scheme as to whether they viewed the schemes as successful and whether they supported it. Respondents felt that the mentors and the mentees were more positive than other stakeholders and rated success in meeting the scheme's stated objectives fairly low (see Figure 1)

\section{Functions and profiles of coordinators}

It was found that the tasks of coordinators tend to be similar across schemes and most coordinators perform the full scope of duties, including planning and designing the scheme, recruiting the mentors and mentees, supporting the mentoring pairs and evaluating and improving the scheme. Other people, such as human resources staff, other internal people, external consultants and trainers, also contribute in many of the functions. Thirty-six per cent of schemes have a steering committee. In the interviews with coordinators it emerged that most coordinators who have a steering committee consider them invaluable to the success of the scheme; however, in one case the existence of a steering committee did not prevent the failure of the scheme.

The research questionnaire attempted to gather information on the number of people who were involved in running the scheme. This question was not always answered in an informative way. However, from the answers obtained, schemes could be ranked in order according to the number of people allocated to them and then compared to the size of the scheme in terms of numbers of mentoring pairs currently active. This analysis seems to indicate that there is little direct relationship between the size of the scheme and the number of people allocated to run the scheme: for example, one scheme had a person spending $10 \%$ of his or her time managing less than five pairs, where another scheme had a person spending $15 \%$ of his or her time managing over 50 pairs. Similarly, schemes with over 100 pairs had resources ranging from 1.4 full-time equivalent people up to 70 people involved in managing the scheme.

In internal schemes, the responsibility for the mentoring scheme falls mainly within the human resources department with two schemes placing it within employment equity and two within its leadership development function.

Most of the coordinators (56\%) did not use information technology tools to help them manage the scheme. Only $12 \%$ used a website or intranet, while a further $36 \%$ used Excel spreadsheets.

Findings related to who the coordinators are included the following: Most (64\%) of the sample coordinators were female. The age distribution shows that $4 \%$ ( 1 person) was under 25 , $44 \%$ were aged between 25 and 35, a further $28 \%$ between 35 and $45,20 \%$ between 45 and 55 and the remaining $4 \%$ between 55 and 65 . The respondents were highly educated - none of them had a qualification of less than a post-Matric certificate and $56 \%$ had a postgraduate degree or equivalent. Most $(56 \%)$ coordinators had been in this role for between 1 and 3 years, $20 \%$ for less than 1 year, $12 \%$ for $3-5$ years and the remaining $12 \%$ for 5 years or more.

Only $16 \%$ of respondents ( $75 \%$ of these in the external schemes) held the coordinator role as a full-time position although $76 \%$ of them were in formal employment. Twenty-four per cent of respondents were volunteers with student or community programmes. Eighty-four per cent of respondents combined the role of mentoring scheme coordinator with other roles, for example, employment equity management, operations management of a consultancy, other human resources development activities and small business development projects.
Most coordinators $(70 \%)$, whether of external or internal schemes, had never managed a mentoring scheme before and $50 \%$ of the coordinators initiated their own role (that is, they started up the project). Seventy-two per cent of respondents said they had been a mentor prior to becoming a coordinator while $60 \%$ had been a mentee. Twenty-five per cent of coordinators have never been either a mentor or a mentee. Sixty per cent of respondents had received no formal training in the role, but $76 \%$ of them were very clear on what was required of them. Sixty-four per cent had no job description for this role. Coordinators of external schemes most typically came from a background in the field in which the mentoring scheme offered its services (for example, small business development), while coordinators of internal schemes tended to come from a human resources background, although there were also examples of coordinators from other functions such as quality assurance and information technology project management. Respondents mentioned a wide range of previous experiences as being usefu to their present role - these included 'project management and a passion for people', 'counselling and coordinating relationships in a school setting' and 'working as an entrepreneurship trainer - moving into mentoring'.

Skills considered to be important for coordinators included interpersonal skills ('good skills and insights into human behaviour [...] able to engage people'), knowledge of the organisation ('understanding in an organisational context what is expected') and project management skills. Respondents felt that the required skills were obtained generally through selfstudy and learning by doing, in the absence of formal training.

\section{How the coordinators experienced their role}

Qualitative data obtained from the study indicated that coordinators raise issues that can be grouped according to various themes - these relate to satisfactions and dissatisfactions in the role, how one develops as a coordinator and advice that could be given to a new coordinator.

In general, it seems that coordinators enjoy their role. Of the seven interviewees, four were mainly positive about their experiences as a coordinator, whilst the other three had either a very negative experience or experienced significant frustrations. The four coordinators who reported mainly positive experiences were all involved with running wellestablished schemes, or, in one case, a scheme which has been running for a short while and is facing a major expansion drive. Two of the coordinators who had had rather negative experiences had been involved in trying to get a scheme off the ground but failed, while the other negative coordinator was in the early stages of implementing a scheme.

Most of the coordinators who responded to the questionnaire find some or much satisfaction in their role. However, three of the coordinators reported no satisfying factors in their role and one reported little satisfaction. All the other respondents cited one or more satisfiers, which can be grouped into three types, namely:

1. Satisfaction at seeing learning and growth among the participants of the scheme

"To see people grow, develop and achieve their dreams and aspirations.'

'Seeing transitions in knowledge, seeing mentees gaining independence and wanting to go on to be mentors.

2. Satisfaction at seeing performance or career improvements 'Seeing businesses thrive'.

'When a young person seizes the opportunity provided by the programme, learns from it, applies it for personal development and growth in own business.

3. Personal satisfaction (for example, sharing experiences and receiving positive feedback)

'Seeing and engaging with the delegates, sharing experiences.'

The degree of satisfaction obtained (if it is obtained) seems to be high, with interviewees describing the experience very 
positively:

[Quotation 1:] 'I love what I'm doing - I think I'm an enabler - enable for potential to come forth, enable to access resources, enable to grow. It's a very, very inspiring role where I'm sitting.' [Quotation 2:] '[...] you just see fantastic things happening and it just feels brilliant. It's quite a varied experience between frustration and great joy."

[Quotation 3:] 'I've discovered the inspiration of these young people - they have very little resources, they have very little skills, but then you come across someone who believes that they can - I am telling you, these young people have been my greatest inspiration in the job.

[Quotation 4:] 'After it's been done for them, people who say I want to be part of this thing and become a mentor, that's one of the things that gives me the motivation to say we're on the right track and this is working.'

The coordinator's role can be extremely frustrating - only three of the coordinators reported no frustrating factors in their role, while many frustrations were reported by the other respondents. These frustrations can be grouped under six main themes, namely:

1. Management support

'lack of management support'

2. Mentor/mentee motivation

'lack of commitment by some mentors'

3. Communication

'unrealistic expectations arising from lack of understanding of what mentoring is'

4. Scheme management / resources

'limited funding' and 'lack of time'

5. Coordinator organisation / resources

'how much effort it takes'

6. Problems with relationships

conflict between mentor and mentee.

'If a mentoring relationship doesn't work and I can see that it's just people issues, it's so frustrating, I wish I could fix this.

'It's [...] frustrating, the mentors who come to do this for themselves - it's like they come in to craft people to become what they think they should be [...] that's not mentoring [...] it frustrates me because [...] if the mentor is coming there for their own glory it inhibits learning and that defeats the objective of the programme.'

Metaphoric descriptions around frustrations included the following:

[Quotation 1:] 'I felt like a fish out of water, because everybody talks about the mentoring, but it's just spoken about [...] and nobody really relates to it.

[Quotation 2:] 'Swimming upstream - a lot of people don't understand the concept behind mentoring.'

Respondents felt that development as a coordinator was largely a self-learning activity or experience passed on from other people. Conducting research was often mentioned as a developmental activity. One mention was made of 'being mentored myself'. Other comments included:

[Quotation 1:] 'You need to read as widely as possible and stay abreast of what the developments are [...] attending presentations and discussing with other people how their programmes are going.' [Quotation 2:] 'Networking with a specific purpose - each session would be almost like a professional upskiller - it's supervision with very specific sessions.

Advice for new coordinators included very practical organisational issues:

[Quotation 1:] 'Make sure you've got the support and backing from the funders or the people who are providing you with the budget and that they understand that your time, how it's divided [...] it's time management [...] make sure you have your time issues sorted out, but the biggest thing is support.'

[Quotation 2:] 'It's quite a difficult role and I think you're competing with a lot of other organisational activities [...] and you've also got to appreciate that people are just sometimes fatigued so I set quite a lot of store by the timing being right.'
[Quotation 3:] 'Understanding priorities, understanding the key elements of the project over the life of the project and planning for those - stakeholder management, that's very important.

\section{DISCUSSION}

As stated, this research study set out to gather information on the characteristics and experiences of mentoring scheme coordinators in South Africa. This had the ultimate objective of being able to make recommendations on how best to support and develop coordinators. Mentoring has great potential in developing human capital in all spheres of life in South Africa and improving the effectiveness of coordinators can make a significant contribution towards realising that potential.

\section{The role of the coordinator}

The findings of this study support the concept that a mentoring scheme coordinator has an identifiable role which is similar across a variety of different mentoring schemes. The study tested whether various tasks, as identified in the literature, were in fact considered to be part of the role of a coordinator. This was found to be true for all schemes, regardless of the variables explored in the study. Mentoring schemes appear on the surface to be diverse (for example mothers with HIV/ AIDS mentoring each other on the one hand and promotion candidates for top executive positions in a corporate environment on the other hand) but this study has shown that, provided that the coordinator has knowledge of the core business of the organisation, coordinators could move between organisations if they wished to become 'professional' mentoring scheme coordinators. This commonality of function also makes it possible to develop standardised training and development materials for coordinators. One of the tasks that is considered very important, both in the literature and in the findings of the study, is monitoring and supporting mentoring pairs. However, this aspect is considered as highly problematic by many coordinators, mainly due to lack of time and other priorities.

In contrast to the commonality around function, is the lack of size or resource relationship. There is little relationship between the size of the scheme and the number of people running it. The reasons for this have not been explored. Lack of resources was frequently mentioned by respondents as a problem in their scheme. Most of these respondents experience significant difficulties in prioritising their tasks and devoting what they see as sufficient time to supporting the mentoring pairs.

Another difference between schemes is the use of a steering committee. It is significant to note that only $36 \%$ of the schemes sampled has a steering committee to guide and/or support the coordinator. In view of the fact that those coordinators who do have a committee believe that this is extremely important to the smooth running and success of the scheme, it would seem that more coordinators could benefit from this type of stakeholder involvement.

Despite one of the common functions of a coordinator being to measure and evaluate the scheme, according to the survey respondents, the study found that most mentoring schemes fail to state the purpose of the scheme in measurable, outcomerelated terms and also that most schemes have not been formally evaluated. This is potentially problematic for coordinators, who would be unable to demonstrate success in achieving their objectives, which may jeopardise the sustainability of the scheme. The research findings identify differences between reactions of various stakeholders to the mentoring scheme (see Figure 1). This supports the proposal by Klasen and Clutterbuck (2002) that success of a mentoring scheme should be evaluated according to various dimensions. They propose a four-outcome model, as shown in Table 3.

The finding that the most positive reactions to the scheme came from the mentors and mentees (see Figure 1) confirms 
conclusions in literature and seems to indicate that the human relationships created through mentoring are valued and produce positive outcomes for the mentors and mentees, at least in personal terms. This result has a powerful impact on the experience of the coordinator, as will be discussed below.

\section{The coordinators and their experiences}

From the findings in terms of the demographics of coordinators, it might be inferred that the role is taken on in early to midcareer, when the person is already at a fairly senior level and the role is held for a fairly short space of time. The role is often self initiated which, together with the findings regarding the mixed results of schemes discussed earlier, might indicate a problem in terms of gaining organisational support - the finding of the relative infrequency of steering committees could support this inference. The relative seniority of the coordinators, although probably useful in gaining credibility for the mentoring scheme, can cause problems in terms of time available and competing priorities - many respondents made comments about the difficulties of being able to devote enough time to running the scheme. In one case, the amount of time devoted to the scheme is as little as $2 \%$ and there were four other cases in which $15 \%$ or less of a person's time was allocated. Although the background of the coordinators varied and few had run a mentoring scheme before, it would seem that most coordinators had had a previous interest in mentoring - this is important for their success as it enhances their passion for the scheme, which is put under pressure when frustrations are encountered.

Appelbaum, Ritchie and Shapiro (1994), cited in Hattingh et al. (2005) emphasised the importance of maintaining the scheme, including having regular contact with the pairs, troubleshooting and problem solving. Interviewees in this study all mentioned this aspect as being important and also as being the source of sometimes satisfying and sometimes frustrating experiences. Positive feedback was experienced as intensely satisfying, while the difficulties of 'nagging' mentoring pairs were reported to be very frustrating - for example, sometimes mentors simply do not make the necessary time available to their mentee, or there is a lack of motivation within the mentoring pair to continue.

Literature sources reviewed in the study mentioned a range of skills considered important for the coordinator. The study confirmed the importance of these in the eyes of practising coordinators. They considered interpersonal and communication skills as critical - it seems that a good 'people's person' is required, who should model good communication skills, including the ability to empathise and listen. Closely linked to these are skills described as 'leadership skills' including good influencing skills. The coordinator's organisational and personal management skills are considered important, with passion, tenacity and drive being mentioned in particular. Freedman (1999) emphasises the difficulty of putting mentoring into action and confirms the importance of these skills. Although both Colley (2003) and Conway (1998) discuss the importance of expertise in mentoring for a coordinator, this was not commonly mentioned in this research study but three of the interviewees in fact conducted considerable personal research into the topic, possibly confirming the point made in the literature. Similarly, although Conway (1998, p. 27) believes that 'culture and values are critical factors in success' of a mentoring scheme, the respondents in this study did not highlight this aspect, with the single exception of one interviewee who described the difficulties that can be experienced if the coordinator tries to operate unaware of the

TABLE 3

Outcomes model for mentoring schemes

\begin{tabular}{lll}
\hline & Relationships & Scheme \\
\hline Process & Measures specific to the & $\begin{array}{l}\text { Measures specific to the } \\
\text { scheme }\end{array}$ \\
scheme & $\begin{array}{l}\text { Measures specific to the } \\
\text { scheme }\end{array}$ & $\begin{array}{l}\text { Measures specific to the } \\
\text { scheme }\end{array}$ \\
\hline
\end{tabular}

Source: Adapted from Klasen \& Clutterbuck (2002, p. 304) organisation's culture. Another skill, only mentioned by one interviewee, is that of volunteer management. This skill is not mentioned in the literature as being important, but when it is considered that mentors are most often volunteers, it is clear that proper management of them is important in keeping mentors involved in the scheme. The interviewee who mentioned this skill had actually been on a specialist course in this aspect.

The findings of this study confirm the statement by Klasen and Clutterbuck (2002) quoted at the beginning of this article, namely that coordinators enjoy the role and feel motivated to do more of it, although this is not a universal experience. The negative experiences referred to in this study arose because of identifiable omissions in ensuring that key success factors are present in the design and implementation of the scheme, which indicates that the negative experiences could be avoided The role seems to have a significant emotional component arising out of both the positive and the negative aspects of the role. Coordinators can experience the role as lonely - they tend to operate as one-man bands, struggling to prioritise and multi-task. The main satisfiers are removed in nature obtained through seeing the success of the mentoring pairs. It would seem that someone who seeks a more direct personal satisfaction would be disappointed in the role. Whether is it worth the frustrations and disappointments was explored nearly all the coordinators found some satisfaction and one interviewee summed it up by saying ' $I$ ' $m$ glad I did it [...] I was quite disillusioned [...] but I'm a lot wiser now', while another said that 'it's inspiring [...] it's brilliant [...] a great joy'. These findings could be used to inform the recruitment and selection process of coordinators - the role should be given to someone who has an interest in the subject and is passionate about the benefits mentoring can bring people. The role is often combined with other roles and therefore people may be promoted or recruited into the role, but if those people do not have the passion, it is unlikely that they will bring the tenacity and drive that is required for success of the mentoring scheme.

\section{Recommendations for development and support of coordinators}

One conclusion drawn from the literature review is that little attention is paid to the development and support of coordinators. This research study confirmed this conclusion. The finding that $68 \%$ of schemes have been running for more than 2 years (of which about half have been running for more than 5 years) confirms the finding of Meyer and Steinman (2008) that 52\% of their sample had been running for more than 3 years and also confirms the conclusions of the literature study that the prevalence of mentoring schemes has increased in the last few years. This can indicate that there are an increasing number of coordinators in the country and therefore an increasing demand for development and support opportunities for them. Development should be based on a clear role definition and profile - a pro-forma job description is offered here (see Figure 2), compiled based on literature and this research study. Based on this, a coordinator can assess their own knowledge and skills gaps and begin to establish development priorities.

Little formal training exists in South Africa for this role and there is little content in the National Qualifications Framework relating to mentoring. The findings of this research study regarding important knowledge and skills for coordinators could form the basis for formalised training and qualifications. One possible source of development could be launching of the some accepted standards for mentoring schemes in South Africa, examples of which were outlined earlier. Another possible source, given the frequency of human resources as a background for coordinators, could be to incorporate the topic into academic and professional programmes in the human resources field, including continuous professional development programmes.

Development activities suggested by interviewees in this research study included case studies and presentations to stay 
Job Title: Mentoring Scheme Coordinator

Position Purpose or Mission: To lead the preparation, design, implementation, on-going support and evaluation of the mentoring scheme so that the identified objectives of the scheme are achieved or exceeded.

Critical Tasks:

1. Project management of preparation, design and implementation of a new mentoring scheme

2. Manage all stakeholder relationships to ensure organisational support for the scheme (this may include fundraising where required)

Lead the scheme management once implemented, including ensuring high levels of support for the mentoring pairs

Manage for close integration of mentoring with other organisational programmes, systems and processes

5. Evaluate and review the scheme against stated objectives, making recommendations for improvements where appropriate.

Competencies, skill, knowledge:

Preferred Education: Evidence of systematic knowledge in the social sciences field at a graduate level.

Preferred Experience: Experience at professional level in Human Resources or the profession in which the mentoring scheme is located.

Other important attributes

Evidence of well above average inter-personal skills, especially listening, empathy and communication skills. A high degree of personal credibility.

2. Evidence of good facilitation skills both with individuals, pairs and groups at all levels

3. Evidence of delivery of successful complex organisational change or community development projects including good project management, multi-tasking and self-organisation skills

4. Evidence of deep organisational knowledge and ability to implement effective change in the prevailing culture, including good influencing/marketing/selling skills

5. Either to have been a mentor or a mentee in a meaningful mentoring relationship.

NOTE: It is critical that the coordinator has an excellent knowledge of mentoring theory and practice, including different possible models and applications, in order to be able to design the scheme to fit the purpose. This knowledge can be acquired prior to or after appointment as the coordinator.

up to date with the latest knowledge in a fast developing field, networking and some form of mentoring or supervision for practising coordinators. The lack of accessible information on schemes in this country and how they work (or do not work), encountered as an obstacle during this research study, hinders sharing of good practices across schemes - few coordinators reported that they network and learn from other schemes. It would seem therefore that there is a need for some institution to provide such activities and here the role of Coaches and Mentors of South Africa (COMENSA) could be important, probably with the support of tertiary level academic institutions.

Support for the coordinators in their role would be appreciated, it would seem, since they experience the role as a lonely one. This can be supplied through networking as discussed above and could also be supplied through some form of recognition scheme - organisations could be encouraged to recognise their mentoring scheme coordinator in their internal recognition systems, or a body such as COMENSA could set up some scheme.

\section{Conclusions and recommendations}

This research study has shown that the function of mentoring schemes in terms of the coordinator as a unit of research is a new field of study in South Africa. The population of mentoring schemes at this point is impossible to estimate and locate, but the research study has shown that even though there is a great diversity of identified schemes, the function and profile of coordinators is common across schemes to a large extent. From the study, it has been possible to make recommendations as to the profiling, development and support of mentoring scheme coordinators.

It might be argued that implementing and maintaining a mentoring scheme is no different than implementing and maintaining any other organisational process such as business planning, performance management or innovation management. This study has shown some of the complexity of mentoring schemes and their management and has been able to offer some suggestions for ways to improve the clarity of the role of the coordinator and suggestions on how to improve the development of the coordinator's skills.
Competent coordination is central to the success of facilitated mentoring.

(Murray, 2001, p. 151)

The most important start point is there needs to be buy-in and commitment from the most senior level in the organisation as to what is going to happen and how it's going to work and who's going to playing which role. If that's not clear, then the coordinator is on a hiding to nothing.

(Interviewee 2)

\section{Limitations of the study}

The lack of information sources to draw from in designing this study and specifically the fact that the coordinator has not been focused on as the unit of analysis in previous research studies, has possibly limited this study in terms of depth and coverage.

The small size of the sample in relation to the likely size of the population limits the validity of the study findings; however, the diversity of the respondents and the high degree of internal consistency in the findings allow preliminary conclusions to be drawn

\section{Suggestions for further research}

Further research aimed at formulating, testing and implementing a model for a formal training programme for mentoring scheme coordinators could help to ensure that structured mentoring schemes are well designed and implemented, thereby delivering on the benefits that mentoring can achieve.

\section{REFERENCES}

Anglo Plat (2009). Sustainable Development Report. Retrieved March 13, 2009, from www.angloplat.com/def_main. asp?Id=sustainable_development/sd_social_impacts/sd_ si_hr/s_i_hr_main.asp

Bryman, A., \& Bell, E. (2003). Business research methods. Oxford: Oxford University Press.

Clutterbuck, D. (2001). Everyone needs a mentor. (3rd edn.). London: CIPD. 
Clutterbuck, D. (2003). Diversity issues in the mentoring relationship. In M.J. Davidson \& COMENSA (2009). Coaches and mentors of South Africa. Retrieved March 13, 2009, from www.comensa.org.za

Colley, H. (2003). Mentoring for social inclusion - A critical approach to nurturing mentor relationships. London: Routledge.

Conway, C. (1998). Strategies for mentoring - A blueprint for successful organisational development. New Jersey: Wiley.

Cresswell, J.W. (2003). Research design - Qualitative,quantitative and mixed methods approaches. (2nd edn.). Thousand Oaks: Sage.

Denzin, N.K., \& Lincoln, Y.S. (2005). The Sage handbook of qualitative research. (3rdedn.). Thousand Oaks: Sage.

DME (2009). Social and labour plan guidelines. Retrieved March 13, 2009, from www.dme.gov.za/pdfs/minerals/ SOCIAL\%2AND\%20LABOUR\%20PLAN\%20GUIDELINES

DPSA (2006). The public service mentorship programme. Retrieved September 30, 2008, from http://www.dpsa.gov.za/ documents/hrd/DPSA_Mentorship.pdf

Egan, G. (1994). The skilled helper: A problem management approach to helping. (5th edn.). Pacific Grove: Brooks/Cole.

Evans, A. (2003). The National Mentoring Pilot Project. In F.K. Kochan \& J.T. Pascarelli (Eds.), Global perspectives on mentoring: Transforming contexts, communities and cultures. Greewich, Conn.: Information Age.

EPWP (2009). Expanded Public Works Programme. Retrieved March13, 2009, from www.epwp.gov.za

Forret, M.L. (1996). Issues facing organisations when implementing formal mentoring programmes. Leadership and Organisation Development Journal, 17(3), 27.

Freedman, M. (1999). The kindness of strangers. Cambridge: Cambridge University Press.

Garvey, B., \& Carter, A. (2004). Editorial. International Journal of Mentoring and Coaching, 2(2).

Gibb, S., \& Megginson, D. (1993). Inside corporate mentoring schemes: A new agenda of concerns. Personnel Review, 22(1), $40-54$.

Gilmore, N., Coetzee, M., \& Schreuder, D. (2005). Experiences of the mentoring relationship in a mining company. $S A$ Journal of Human Resource Management /SA Tydskrif vir Menslikehulpbronbestuur, 3(3), 27-32.

Hattingh, M., Coetzee, M., \& Schreuder, D. (2005). Implementing and sustaining mentoring programmes: A review of the application of best practices in the South African organisational context. SA Journal of Human Resource Management, 3(3), 40-48.
IMA (2009). International Mentoring Association. Retrieved May 15, 2009, from http://www.mentoring-association.org

ISMPE (2009). International Standards for Mentoring Programmes in Employment. Retrieved March 12, 2009, from http://www. ismpe.com/ismpe_home.php

Jobs Summit (1998). Summary of Jobs Summit Declaration. 30 October 1998. Retrieved March 13, 2009, from www.labour gov.za/doc/policy/summit.html

Klasen, N., \& Clutterbuck, D. (2002). Implementing mentoring schemes. Oxford: Butterworth Heinemann.

Kochan, F.K. (2002). The organisational and human dimensions of successful mentoring programs and relationships. Connecticut Information Age.

Kochan, F.K., \& Pascarelli, J.T. (2003). Global perspectives on mentoring: Transforming contexts, communities and cultures. Connecticut: Information Age.

Mentfor (2009). Programme search. Retrieved May 07, 2008, from http://www.mentfor.co.uk/ProgrammeSearch.asp

Merriam, S.B. (1998). Qualitative research and case study applications in education. San Francisco: Josey Bass.

Meyer, M., \& Steinman, N. (2008). First National Coaching and Mentoring Benchmarking Study, Phase 1 Results. Paper presented at the Knowledge Resources Coaching and Mentoring Conference, March 13 2008, Johannesburg, South Africa.

Murray, M. (2001). Beyond the myths and magic of mentoring. San Francisco: Josey Bass.

Peer Resources Network (2009). Peer Resources Network. Retrieved March 13, 2009, from www.mentors.ca

Philips, J.J., \& Stromei, L.K. (2001). Creating mentoring and coaching programs. Alexandria: ASTD Press.

SAQA (2009). South African Qualifications Authority Unit Standard 115432. Retrieved March 13, 2009, from http://regqs.saqa. org.za/viewUnitStandard.php?id=115432

Shank, G.D. (2002). Qualitative research - A personal skills approach New Jersey: Merrill Prentice Hall.

Shiner, M., Young, T., Newburn, T., \& Groben, S. (2004). Mentoring disaffected young people - An evaluation of mentoring plus. Joseph Rowntree Foundation. Retrieved March 12, 2009, from http://www.jrf.org.uk/publications/mentoringdisaffected-young-people-evaluation-mentoring-plus

Stewart, M., \& Parr, N. (2008). Bridging the GAP through mentorship. People Dynamics, 26(8), 9-10. 